\title{
The Relationship between Online Interaction and Resilience: The Mediating Role of Online Social Support
}

\author{
Liu Dong*, Tang Kuiyu and Hou Bowen \\ School of Sociology, Department of Humanities and Social Sciences, Harbin \\ Institute of Technology, China \\ 12B916003@hit.edu.cn,tangky@hit.edu.cn,13B916004@hit.edu.cn
}

\begin{abstract}
This study investigated the university students' resilience through online interaction's view within a social cognition framework, in China. 525 college students were asked to complete a questionnaire consists of The Online Interaction Level Scale, the Online Social Support Scale of Adolescence and the Conner-Davidson Resilience Scale. Research Data was analyzed by using the structural equation modeling (SEM) method. The results indicated as follows: (1) The total average score of college students' online interaction, online social support and resilience level were higher than medium critical value; (2) There was no difference in male and female's resilience. (3) College students' online interaction and online social support were all the positive predictor of resilience; (4) The effect of resilience of online interaction was fully mediated by online social support. By introducing the perspective of online interaction into the research of resilience, meanwhile adding new complement to the traditional structure, this study provides a new view and approach to the resilience construction research.
\end{abstract}

Keywords: online interaction; online social support; resilience; mediating role

\section{Introduction}

As a new issue of positive psychology and social work, the term of resilience has been variously used to imply a substance of elastic qualities, presenting the capacity for successful adaptation to a challenge and threatening circumstance, and the character of hardiness and invulnerability [1]. Although definitions of resilience vary among researches, a consensus view is that resilience describes an invulnerability to stress and an ability to recover from negative events and environment [2]. It means the "normal development under difficult conditions" [3]. Recently, resilience has been conceptualized as a dynamic process involving an interaction between both internal and external risk and protective processes [4]. The college students who live in Chinese social transformation period, face the complex competitive relationship, multiple values, the growing differentiation of social classes and the changes in family structure. During school life, each student may meet the negative situation of learning, examinations, love, internship and graduation which are the challenge to their physical and mental health. Therefore, resilience is gradually becoming the key to students' development. Protective factors of students' resilience have commonly been discussed within three broad areas: individual young people (one's competence, talent and skill), his family and the societies in which he live [5]. Studies of the protective factors of resilience have focused on contextual factors - an individual's family, neighborhood, school, peer network, or work settingmight contribute to resilience [6]. However, there is little attention has been paid to the online interaction of college students. 
According to the Thirty-sixth Statistical Report on Internet Development from the China Internet Network Information Center, there are 668 million Chinese people who are now surfing the internet. The internet penetration rate of China is $48.8 \%$, and a network society is gradually mature [7]. Students' group is the largest group of Chinese internet users, accounting for $26.4 \%$. Online interaction is becoming increasingly common in college students [8], which even has affected the college students' cognition, emotion, behavior and lifestyle. It is interesting to take a deep look at that whether online interaction network will influence the level of students' resilience in daily reality. Furthermore, it is also valuable to investigate that What's the role of online interaction in the process of student's resilience construction. Paying particular attention to these concerns, this paper explores the internal mechanism of online interaction and resilience.

\section{Literature Review and Hypotheses}

Resilience is increasingly recognized as a multi-discipline, multi-professional concept and practice [9], which is conceptualized as " a process of or capacity for, or the outcome of successful adaptation despite a changing environment" [10]. The concept of resilience refers to the presence of developmental competences in living conditions [11], and the dynamic interactive process of psychological conditions and external environment, which included three parts: stress life events, risk factors and protective factors [12]. The protective factor is the personal or environmental factor which can encourage individual actor coping with the stress and hardship to reduce negative outcomes [13]. Researches about youngsters protective factors points out that those factors may promote resilience, such as schools, families, peer groups and relationships with supportive adults [14]. Researchers suggested that cognitive ability may exert a protective effect in neglectful environment [15].

With the wide use of internet, more and more researchers have begun to pay attention to the functions and influences of the internet, such as relationship formation, interpersonal trust, information sharing and social adaption [16]. Some researchers have indicated that the main function of the Internet has changed from information seeking to interpersonal interaction [17]. Online interaction has gradually become an important way for college students to have inter-personal interaction, either to develop relationships with strangers or to maintain friendships which is existing [8]. Online interaction is not only an individual behavior, but also an important way for social interaction. The anonymity of the cyberspace, becomes a new and important additional part to "real life", at the same time prompts a direct individual expression reflecting their true personal inner feelings, weaknesses, and even personal privacy [18]. To some extent, online interaction provides new and imaginative solutions for college students to overcome the difficulties in daily life.

Some researchers indicated that online interaction was found to decrease loneliness and depression significantly, meanwhile to perceive social support and self-esteem. Online interaction could be helpful to adolescents who were lack of social support, endowing them the ability to establish new relationships and seeking interpersonal supportive which cannot be achieved in real life [19]. The convenience and low cost of network communication make both sides of internet user become a social support provider and receiver [20]. Due to the unique feature of network, online social support is more attractive than offline social support [21]. The online social support of college students had a significant effect on subjective well-being, positive emotions and life satisfaction [22]. Based on the interaction in the virtual space, adolescents have processed emotional communication and information exchange. During this period they have built a sense of identity and belonging through the certain social interaction. With mutual understanding 
and respect enhanced, their ability to face the difficulties and setbacks of life reality at the same time.

Above studies showed that online social support can provide a buffering mechanism between online interaction and resilience. More specifically, resilience among students may be mediated by online social support. Therefore, this study investigated this potential mediating relationship to enhance current understanding regarding the roles of online social support in relation to students' online interaction and resilience. Bandura [23] proposed a social cognition model, including individual behavior, cognition and environment. Based on the dynamic interaction model, this study proposed the following hypothesis.

H1: Online interaction positively predicts resilience.

$\mathrm{H} 2$ : Online social support positively predicts resilience.

H3: Online social support mediates the relationship between online interaction and resilience.

According to the literature and hypotheses discussed previously, we established a hypothetical model, as shown in Figure 1.

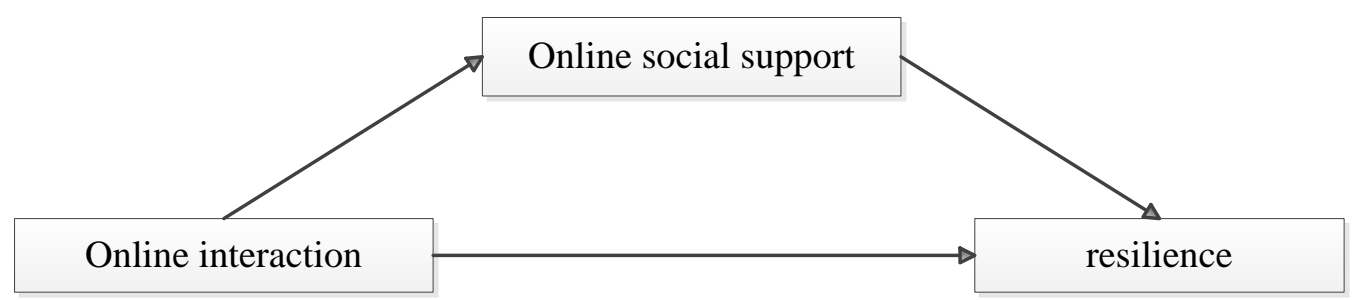

Figure 1. Hypothetical Models Diagram

\section{Methods}

\subsection{Participants}

The participants who completed the survey were university students. Using cluster sampling, we chose eight classes of four grades from a comprehensive university in Heilongjiang province. 525 questionnaires were distributed and completed. The average response time for the scales was approximately $25 \mathrm{~min}$. Questionnaires with no or neutral responses were considered invalid, therefore which were eliminated from the study sample. After the elimination, the number of valid questionnaires recovered was 500 (a recovery rate of $95.2 \%$ ) at last used in the analysis. 144 of which were completed by freshmen (28.8\%), 148 were sophomores (29.6\%), 126 were juniors (25.2\%), and 82 were seniors $(16.4 \%)$. In total, 267 of the respondents were male (53.4\%) and 233 were female $(46.4 \%)$.

\subsection{Measures}

For students' online interaction scale, we referenced the scale employed by Fan [24], and retained 10 items in the final version. For this scale, a five-point Likert scale $(1=$ not concerned to $5=$ very concerned) was adopted. Validity was measured using exploratory actor analysis and confirmatory factor analysis. The KMO was 0.739 , and the Bartlett' $\mathrm{s}$ sphericity test yielded v2 $(45)=1289.183(\mathrm{p}<.001)$. The Cronbach's $\alpha$ for all items was $0.784, \chi 2 / \mathrm{df}=4.721, \mathrm{GFI}=0.921, \mathrm{NFI}=0.849, \mathrm{CFI}=0.876, \mathrm{RMSEA}=0.086$, indicating superior reliability and validity. 
Based on previous studies of Liang [25], we compile this scale of 13 items. A fivepoint Likert scale ( $1=$ strongly disagree to $5=$ strongly agree) was used to obtain the scale scores. The KMO measure of sampling adequacy was 0.864, and the Bartlett's sphericity test yielded v2 $(78)=2570.011(\mathrm{p}<.001)$. Finally, we identified three factors: online information support, online emotion support and online friendship support. The Cronbach's $\alpha$ of all items was $0.846, \chi^{2} / \mathrm{df}=3.187$, GFI $=0.944$, NFI $=0.924, \mathrm{CFI}=$ 0.946 , RMSEA $=0.066$, indicating superior reliability and validity.

Resilience level scale used the Connor-Davidson resilience scale (CDRS), which retained 25 items, and a four-point Likert scale $(1=$ strongly disagree to $4=$ strongly agree) was used to obtain the scale scores. Higher scores for the scale indicated greater level of resilience. Lower scores for this scale implied fewer resilience. Five factors were included to reasonably assess the psychological traits concerning resilience: (1) material management and use (7 items); (2) applicability of dilemma (9 items), (3) self control (4 items); (4) optimism and hopefulness (3 items) and (5) belief and faith (2items). The Cronbach's $\alpha$ of all items, which measured their internal consistency, was 0.901 , and $\chi^{2}$ / $\mathrm{df}=3.933, \mathrm{GFI}=0.856, \mathrm{NFI}=0.778, \mathrm{CFI}=0.823, \mathrm{RMSEA}=0.07$, indicating superior validity and reliability.

Bi-variate correlations were used to assess the relationships between variables by SPSS22.0. Results from SEM was conducted using AMOS22.0.

\section{Results}

\subsection{Descriptive Statistical}

In order to present the overview of data, a figure calculating all respondents mean value by every scale has been given as follow. Mean statistics for online interaction, online social support, and resilience are presented in Table1. Mean levels of online interaction and online social support were 3.37 and 3.45, generally higher than threshold value 3 points. The mean of resilience was 2.83 significantly higher than threshold value 2.5 points.

Table 1. Descriptive Statistical Analysis

\begin{tabular}{|c|c|c|c|}
\hline MEASURE & online interaction & online social support & resilience \\
\hline$(\mathrm{M} \pm \mathrm{SD})$ & $3.37 \pm 0.51$ & $3.45 \pm 0.59$ & $2.83 \pm 0.46$ \\
\hline
\end{tabular}

\subsection{Difference between Gender}

An independent t-test was done to determine differences between gender. Independent t-test can be done on the premise of that the distribution of gender on the three factors have equal variance, so a Levene test had been done, results are shown in Table 2.

Table 2. Difference between Gender

\begin{tabular}{|c|c|c|c|c|c|c|}
\hline \multirow{2}{*}{ Variable } & \multicolumn{2}{|c|}{ Levene's Test } & \multicolumn{4}{|c|}{ Independent T-Test } \\
\cline { 2 - 7 } & $\mathrm{F}$ & sig & Female & Male & F & Sig. \\
\hline Online interaction & 8.253 & 0.004 & 3.39 & 3.35 & 0.858 & 0.355 \\
\hline Online social support & 5.457 & 0.020 & 3.45 & 3.45 & 0.009 & 0.926 \\
\hline Resilience & 2.783 & 0.096 & 2.83 & 2.83 & 0.054 & 0.816 \\
\hline
\end{tabular}


The sign Value of resilience is more than 0.05 , which means that could be analyzed by independent t-test. The results of independent t-test are shown in Table 2, the $t$ value between gender and resilience is 0.233 , and sig. value is 0.816 , which means that there was no difference in male and female's resilience.

\subsection{Correlation Analysis}

Correlation coefficients for all variables included are presented in Table 3. Table 3 shows significant correlations between online interaction, online social support, and resilience. Online interaction had a significantly positive correlation with online information social support, online emotion support and online friendship support ( $\mathrm{p}$ $<0.001)$, and the factors of resilience $(\mathrm{p}<0.001)$. However, a significant correlation was not observed between online information support and material manage and use $(\mathrm{p}>0.05)$. Significant positive correlations were observed between other factors of resilience and online information support $\mathrm{p}<0.001)$, online emotion support( $\mathrm{p}<0.001)$, and online friendship support $(\mathrm{p}<0.001)$.

Table 3. Inter-Correlations for Measures

\begin{tabular}{|c|c|c|c|c|c|c|c|c|c|}
\hline & 1 & 2 & 3 & 4 & 5 & 6 & 7 & 8 & 9 \\
\hline 1 & 1 & & & & & & & & \\
\hline 2 & $.533^{* *}$ & 1 & & & & & & & \\
\hline 3 & $.429^{* *}$ & $.351^{* *}$ & 1 & & & & & & \\
\hline 4 & $.475^{* *}$ & $.345^{* *}$ & $.397^{* *}$ & 1 & & & & & \\
\hline 5 & $.250^{* *}$ & .055 & $.094^{*}$ & $.245^{* *}$ & 1 & & & & \\
\hline 6 & $.359^{* *}$ & $.263^{* *}$ & $.196^{* *}$ & $.370^{* *}$ & $.685^{* *}$ & 1 & & & \\
\hline 7 & $.310^{* *}$ & $.190^{* *}$ & $.131^{* *}$ & $.297^{* *}$ & $.528^{* *}$ & $.616^{* *}$ & 1 & & \\
\hline 8 & $.197^{* *}$ & $.111^{*}$ & $.149^{* *}$ & $.227^{* *}$ & $.522^{* *}$ & $.567^{* *}$ & $.455^{* *}$ & 1 & \\
\hline 9 & $.155^{* *}$ & $.093^{*}$ & $.092^{*}$ & $.180^{* *}$ & $.322^{* *}$ & $.337^{* *}$ & $.363^{* *}$ & $.321^{* *}$ & 1 \\
\hline
\end{tabular}

1.online interaction; 2.online information support; 3.online emotion support; 4.online friendship support; 5.material manage and use; 6.applicability of dilemma; 7. self control; 8.optimism and hopefulness;9.belief and faith.

$(* . p<0.05 . * *<0.01$. )

\subsection{Assessing Model Fitness}

Use Amos software 22.0 to establish the structural equation model. Firstly, put online interaction level as the predictor and resilience as the outcome variable to build Model 1. Secondly, put online interaction as the predictor and online social support as the outcome variable to build Model 2. Thirdly, put online social support as the predictor and resilience as the outcome variable to build Model 3. Then build Model 4 include a predictor of online interaction level, mediator variable is online social supports, and the outcome variable was resilience (Figure 2.) 


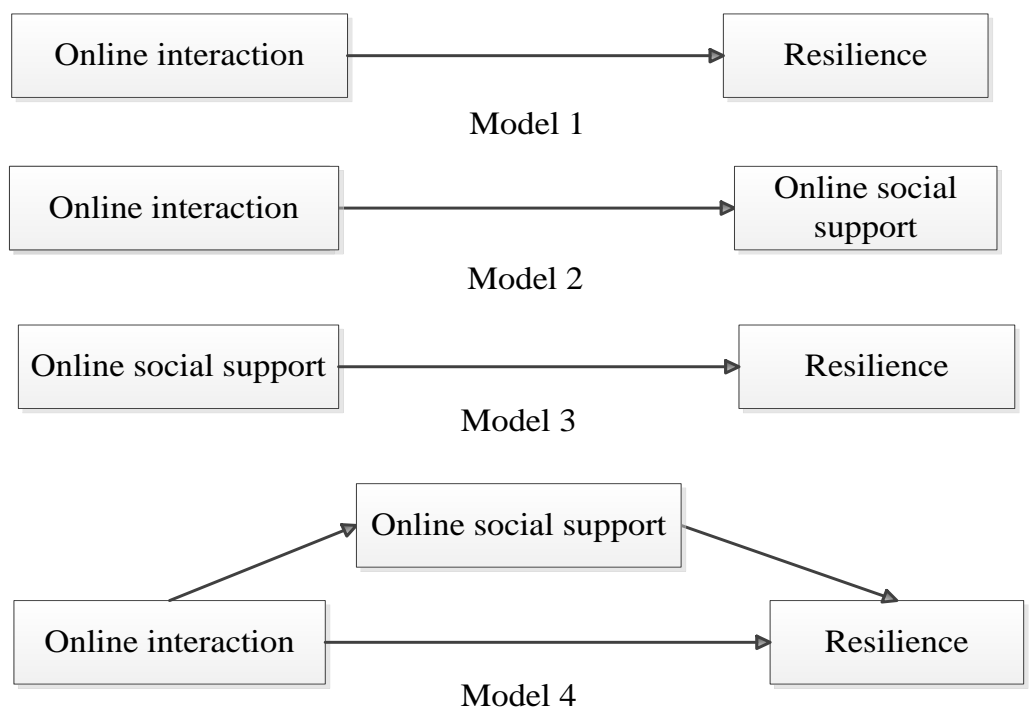

Figure 2. Model of Research

As indicated by the analysis results, the measurement model provided adequate fit to the data. $x^{2}=21.016, x^{2} / d f=2.335, \mathrm{GFI}=0.986, \mathrm{CFI}=0.987, \mathrm{NFI}=0.987, \mathrm{IFI}=0.978$, RMSEA $=0.052$. The GFI, CFI, NFI, and IFI, greater than 0.90 and RMSEA less than 0.08. College students' online interaction was positive predictor of resilience ( $\beta=0$. $31, \mathrm{p}<0.001$ ), and the path coefficient was 0.8 . Hypothesis 1 of this study was proved.

Table 4. Model Fit Index

\begin{tabular}{|l|l|l|l|l|l|l|r|}
\hline & $\chi^{2}$ & $\chi^{2} / \mathrm{df}$ & GFI & CFI & NFI & IFI & RMSEA \\
\hline Model 1 & 21.016 & 2.335 & 0.986 & 0.987 & 0.987 & 0.978 & 0.052 \\
\hline Model 2 & 7.977 & 3.989 & 0.992 & 0.986 & 0.982 & 0.986 & 0.077 \\
\hline Model 3 & 59.147 & 3.113 & 0.972 & 0.965 & 0.966 & 0.950 & 0.065 \\
\hline Model 4 & 78.209 & 3.128 & 0.967 & 0.963 & 0.947 & 0.963 & 0.065 \\
\hline
\end{tabular}

From Figure 3 and Table 4, the Model 2 was $\chi^{2}=7.977, \chi^{2} / \mathrm{df}=3.989$, GFI $=0.992$, $\mathrm{CFI}=0.986, \mathrm{NFI}=0.982, \mathrm{IFI}=0.986, \mathrm{RMSEA}=0.077$. Online interaction positive influence online social support $(\beta=0.8, \mathrm{p}<0.001)$.

The measured goodness-of-fit of Model 3, which was satisfactory, was $\chi^{2}=59.147, \chi^{2}$ / $\mathrm{df}=3.113, \mathrm{GFI}=0.972, \mathrm{CFI}=0.965, \mathrm{NFI}=0.966, \mathrm{IFI}=0.950, \mathrm{RMSEA}=0.065$. There is significant direct effect between online social support and resilience, and the path coefficient was $0.7(\beta=0.37, p<0.001)$. Hypothesis 2 of this study was proved.

The measured goodness-of-fit of Model 4 , which was satisfactory, $\chi^{2}=78.209, \chi 2 / \mathrm{df}=$ $3.128, \mathrm{GFI}=0.967, \mathrm{CFI}=0.963, \mathrm{NFI}=0.947, \mathrm{IFI}=0.963, \mathrm{RMSEA}=0.065$. Online interaction of college students was positive effect online social support $(\beta=0.78, p<$ $0.001)$. Online social support was the positive influence resilience $(\beta=0.34, p<0.01)$. But the influence coefficient of online interaction to resilience was not significant $(\beta=$ $0.04, \mathrm{p}=0.736>0.05)$. 


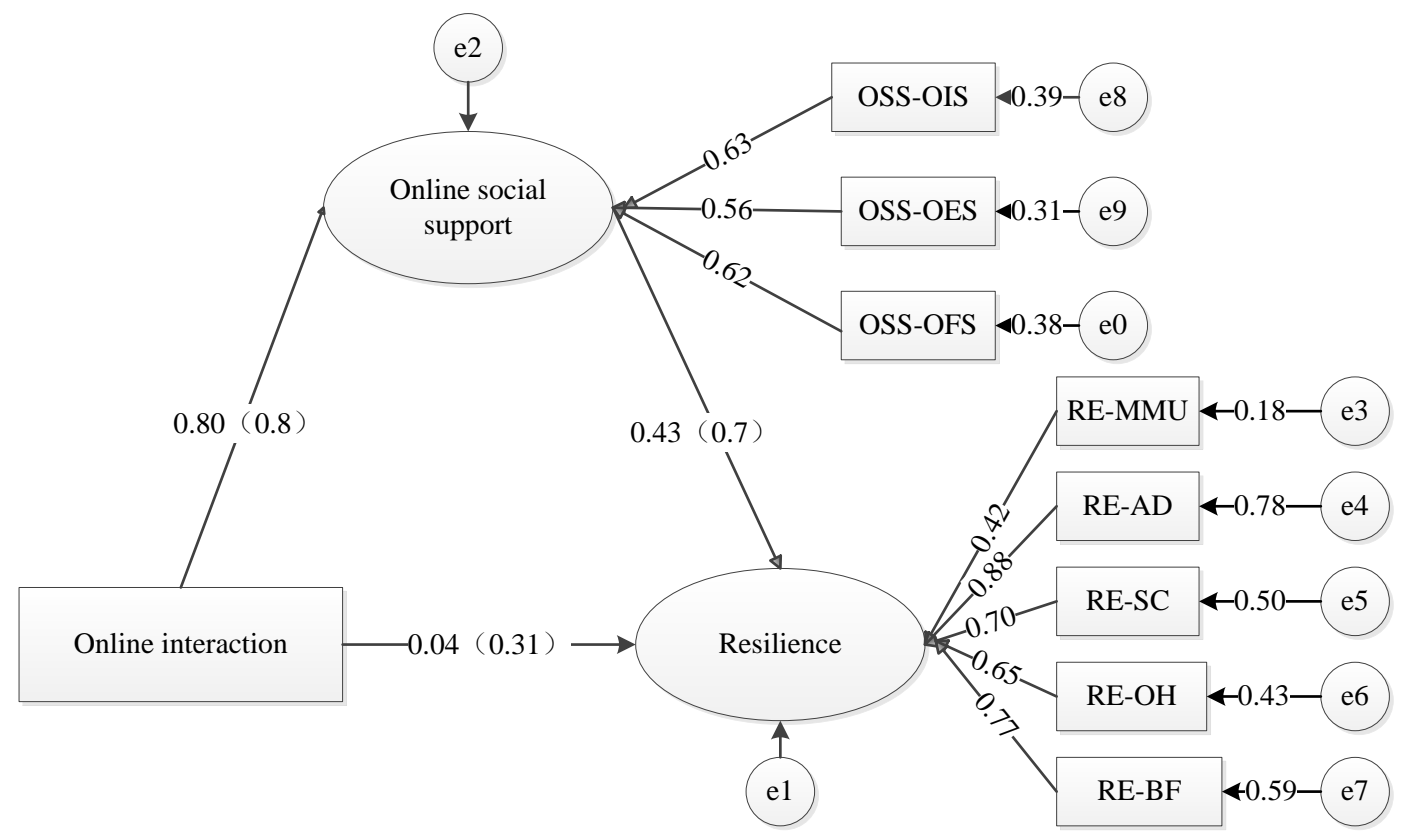

Figure 3. The Finalized Structured Model

\subsection{Mediation Analysis}

The equations used to estimate the basic intervening variable model are shown in Equations 1, 2, and 3 and are depicted as a path model in Figure 6.

$$
\begin{gathered}
Y=\beta 0(1)+\tau X+\varepsilon(1) \\
Y=\beta 0(2)+\tau^{\prime} X+\beta M+\varepsilon(2) \\
M=\beta 0(3)+\alpha X+\varepsilon(3)
\end{gathered}
$$

In these equations, $\mathrm{X}$ is the independent variable (online interaction), $\mathrm{Y}$ is the dependent variable (resilience), and $\mathrm{M}$ is the intervening variable(online social support). $\beta 0(1), \beta 0(2), \beta 0(3)$ are the population regression intercepts in Equations 1, 2, and 3, respectively, $\tau$ represents the relation between the online interaction and resilience in Equation 1, $\tau$, represents the relation between the online interaction and resilience variables adjusted for the effects of online social support which is the intervening variable in Equation 2, $\alpha$ represents the relation between online interaction and online social support in Equation 3, $\beta$ represents the relation between online social support and the dependent variables of resilience adjusted for the effect of the independent variable online interaction in Equation 2, and $\in(1), \in(2)$, and $\in(3)$ are the residuals in Equations 1, 2 ,and 3, respectively. Throughout the whole article, assume that continuous $\mathrm{X}, \mathrm{M}$, and $\mathrm{Y}$ had a multivariate normal distribution and that error terms were normally distributed (Mac, Lockwood, 2002) . (Figure 6 ) 


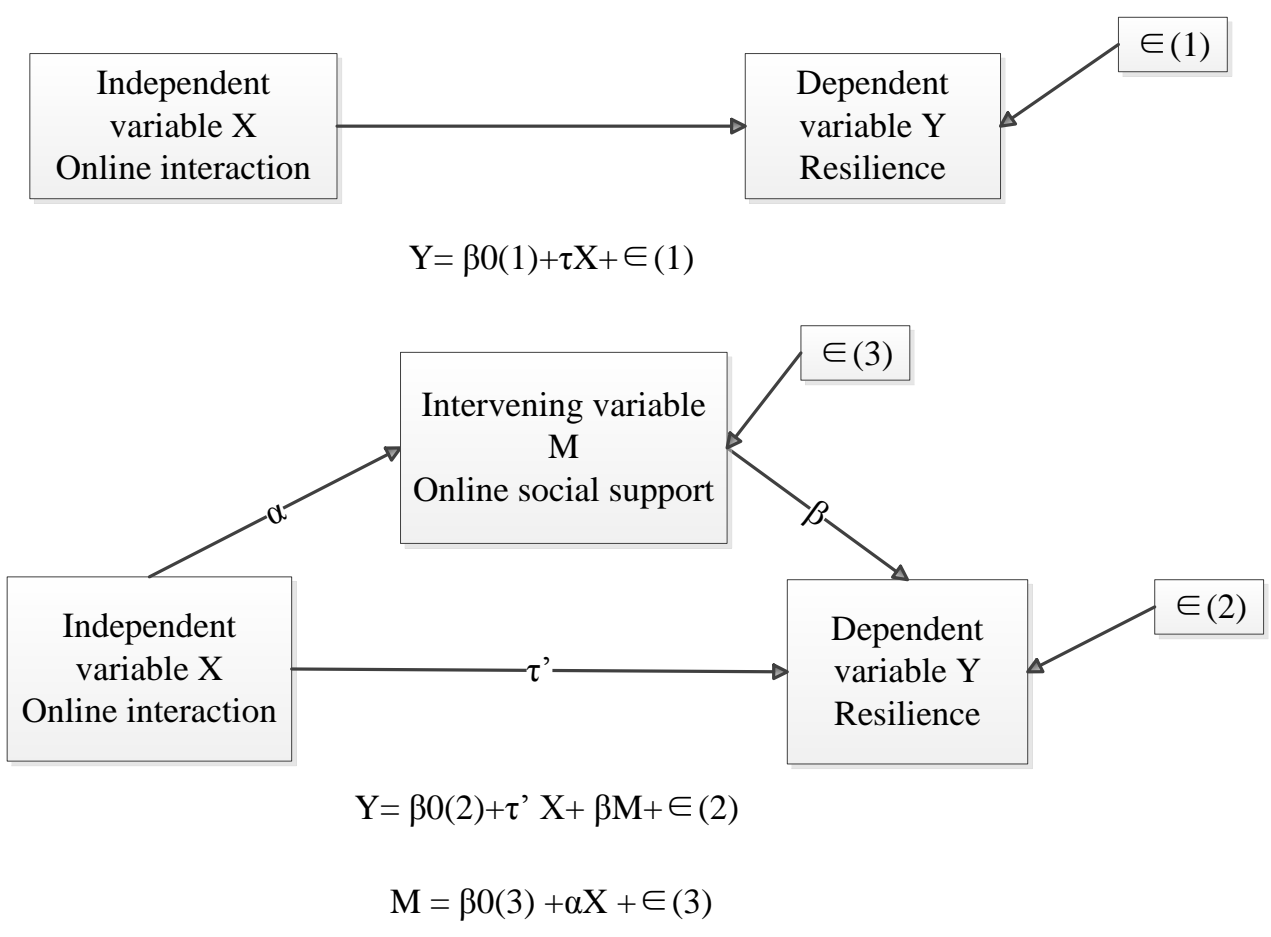

\section{Figure 4. Path Diagram and Equations for the Intervening Variable Model}

According to Baron and Kenny's research, mediation should satisfies three allowing conditions: (a) "the independent variable significantly account for the presumed mediator" ; (b) "the mediator significantly account for the dependent variable", and (c) "When Paths $\mathrm{a}[\alpha]$ and $\mathrm{b}[\beta]$ are controlled, a previously significant relation between independent and dependent variables is no longer significant, with the strongest demonstration of mediation occurring when Path c [ $\left.\tau^{\prime}\right]$ is zero".

The standardized data for the test of the overall structural model is presented in Figure 6. Variations in levels of online interaction of college students significantly account for variations in the online social support (Ho: $\alpha=0)$. Variations in the online social support significantly account for variations in the resilience (Ho: $\beta=0)$. And when Paths $\alpha$ and $\beta$ are controlled, path coefficient from 0.31 down to 0.04 , and a previously significant relation between independent and dependent variables is no longer significant (Ho: $\tau^{\prime}=$ 0 ). Based on the above data and analysis, full mediation of online social support was observed between online interaction and resilience. Hypothesis 3 of this study was validated.

\section{Discussion}

The results of the survey showed good indicts of the model fit. In contrast to earlier resilience studies emphasized on the contributions of practical protective factor, findings in this paper provided empirical evidence to support the theoretical model of online protective factor in understanding youth resilience. Furthermore, it also suggested that the theoretical model of how the interrelationships of online interaction, online social support and resilience are relevant to youth mental health and social work in Chinese context.

Firstly, results demonstrated that College students' online interaction and online social support were all higher than medium critical value. The findings provided strong evidence that the level of resilience of university students was significantly associated with the 
level of online interaction. At the same time, online communication contributes positively to individual's optimism, hopefulness, belief and faith which are factors of resilience and important to daily life. Therefore, online interaction provides a new solution for college students to cope with the plight of reality.

Secondly, the study categorized college students' online social support into online information support, online emotion support and online friendship support. Results also shows that college students' online social support helps college students to expand their support networks, which is in accordance with the early study [26].

Thirdly, Students' online social support has significantly positive effect to resilience [27]. In addition that online social support can be a psycho-social mechanism in the relationships between online interaction and resilience.

At last, as expected, the fully mediating effect of online social support was confirmed through SEM, which is consistent with earlier studies suggesting a relationship between social support and resilience. The current findings indicate that the satisfaction, emotion and information through online interaction can somewhat promote one's social support just like face-to-face interaction, which increase students' optimism, hopefulness, life adaptability and the ability to deal with dilemmas in daily life [22].

\section{Limitations and Implications}

Several limitations may have influenced these results. Firstly, the cross-sectional design of the investigation and the university student self-report survey limited this study's assessment of the causal relationships. Secondly, the students who took the survey were just from one university in Heilongjiang Province, which may have an impact on the promotion of research results. In addition, the results suggest that there are significant relationship between online interaction, online social support and resilience, but did not distinguish the factors of online interaction and without putting them in to the structural equation model. Future research with a greater sampling scope and variables is recommended to verify the results of this study.

\section{Acknowledgment}

The author would like to thank the young respondents who kindly answered the questionnaires. This article dedicates to those who had spare no effort to doing research on Resilience study.

\section{References}

[1] C. A. Olssona, L. Bonda, J. M. Burnsb, D. A. V. Brodrickc and S. M. Sawyerd, "Adolescent resilience: a concept analysis", Journal of Adolescence, vol. 11, (2003), pp. 1-3.

[2] N. Garmezy, "Resilience in children's adaptation to negative life events and stressed environments", Pediatric Annals, vol. 20, (1991), pp. 459-466.

[3] P. Fonagy, M. Steele, H. Steele, A.Higgitt and M. Target, "The theory and practice of resilience", Journal of Child Psychology and Psychiatry and Allied Disciplines, vol. 35, (1994), pp. 231-257.

[4] M. Rutter, "Resilience in the face of adversity: Protective factors and resistance to psychiatric disorder", British Journal of Psychiatry, vol. 147, (1985), pp. 598-611.

[5] E. E. Werner and J. L. Johnson, "The role of caring adults in the lives of children of alcoholics", Substance Use and Misuse, vol. 39, (2004), pp. 699-720.

[6] Y. L. Liu, "West resilience theory: transformation, evolution, arguing and development", Social Sciences Abroad., vol.6, (2011), pp. 67-74.

[7] K. Y. Tang, "Interpretation of the Network Society and Its Social Ontology", Journal of HIT (Social Sciences Edition), vol. 16, no. 1, (2014), pp. 6.

[8] A. Lenhart, M. Madden and P. Hitlin, "Teens and technology: Youth are leading the transition to a fully wired and mobile nation", Pew Internet and American Life Project, Washing-ton, DC, (2005). 
[9] L. Tonmyr and C. Wekerle, "Risk and resilience in association with child maltreatment", Child Abuse and Neglect, vol.37, no. 1, (2013), pp. 2.

[10] E. M. Cummings, A. L. Greene and K. H. Karraker, "Life span developmental psychology: Perspectives on stress and coping", Lawrence Erlbaum Associates, New Jersey, (1991).

[11] A. S. Masten, "Resilience in developing systems: Progress and promise as the fourth wave rises", Development and Psychopathology, vol. 19, no. 3, (2007), pp. 921-930.

[12] L. L. Han, "Resilience, Risk Factors and Protective factors of Students with Learning Difficulties", Journal of Capital Normal University (Social Sciences Edition), vol. 5, (2014), pp. 119.

[13] Y. P. Li, "New Trends in Youth Research: Resilience Review", Youth Studies., vol. 5, (2005), pp. 1-4.

[14] K. L. Kumpfer, "Factors and Processes Contributing to Resilience: The Resilience Framework", Resilience and Development, Kluwer Academic, New York, vol. 3, (1999), pp. 179-224.

[15] A. D. Kimberly, S. W. Cathy and J. C. Sally, "Predictors of resilience in abused and neglected children grown-up: The role of individual and neighborhood characteristics", Child Abuse \& Neglect., vol. 31, no. 3, (2007), pp. 255- 274

[16] C. N. Li, X. X. Shi and J. N. Dang, "Online communication and subjective well-being in Chinese college students: The mediating role of shyness and social self-efficacy", Computers in Human Behavior, vol. 34, (2014), pp. 89-95.

[17] P. M. Valkenburg and J. Peter, 'Preadolescents' and adolescents' online communication and their closeness to friends", Developmental Psychology, vol. 43, no. 2, (2007), pp. 267- 277.

[18] J. B. Walther, "Computer-mediated Communication: Impersonal, Interpersonal and Hyper-personal Interaction”, Communication Research., vol. 23, no. 1, (1996), pp. 3- 43.19.

[19] R. Kraut, S. Kiesler, B. Boneva, J. Cummings, V. Helgeson and A. Crawford, "Internet paradox revisited", Journal of Social Issues, vol. 58, no.1, (2002), pp. 49 -74. 20.

[20] D. Q. Ding, N. Xiao and X. Y. Zhang, "Relationships between Life Events, Online Social Support and Internet Addiction Disorder", Journal of Educational Science of Hunan Normal University, vol. 12, no. 6, (2013), pp. 118. 21

[21] X. J. Sun, J. Zhao, Z. K. Zhou, T. X. Xie and Y. N. Tong, "The Relationship between Online Social Support and Online Interpersonal Trust of College Students: A Moderated Mediation Model", Psychological Development and Education., vol. 31, no. 2, (2015), pp. 129-136.22.

[22] X. L. Zheng, "The Relationship Between Reality Altruistic Behavior and Internet Altruistic Behavior: the Role of Online Social Support", Psychological Development and Education, no. 1, (2013), pp. 31-37.

[23] A. Bandura, "Self-efficacy mechanism in human agency", American Psychologist, vol.37, no. 2, (1982), pp. 122-147.

[24] X. P. Fan and G. Q. Ma, "A Study on the Impact of Interactivity on Online Purchasing Intent Based on Virtual Community”, Journal of Zhejiang University (Humanities and Social Sciences), vol. 39, no. 5, (2009), pp. 151.

[25] X. Y. Liang and H. S. Liu, "The structure of Youth Online Social Support”, Educational Research and Experiment, no. 2, (2010), pp. 83-87.26.

[26] H. H. Zhao, H. Y. Zhang, Q. X. Liu, F. X. Wang and Z. K. Zhou, "College Students' Trait Empathy and Internet Altruistic Behavior: The Mediating Effects of Online Social Support", Psychological Development and Education, no. 5, (2012), pp. 478-485.

[27] C. X. Yang, Y. C. Caixia and W. Wang, "College Students' Social Support and Coping Style: Mediator Effect of Resilience", China Journal of Health Psychology, vol. 22, no.7, (2014), pp. 1066. 